\title{
The regulation of informed consent to participation in clinical research by mentally ill persons in South Africa: An overview
}

\author{
A Nienaber, BA (Hons), LLB, LLM, LLD, Dipl Datametrics \\ Faculty of Law, University of Pretoria
}

The article examines the legal requirements relating to the informed consent of mentally ill persons to participation in clinical research in South Africa. First, the juridical basis of informed consent in South African law is outlined; and second, the requirements for lawful consent developed in South African common law and case law are presented. Finally, the article deliberates upon the requirements for the participation of mentally ill persons in research as laid down by the Mental Health Care Act and its regulations, the National Health Act and its (draft) regulations, and the South African Constitution.

Informed consent is a primary precondition of legal and ethical clinical research and is regarded as the 'cardinal principle for judging the propriety of research with human beings'. ' Based on the ethical principle of respect for personal autonomy, informed consent flows from the recognition that all persons have unconditional worth. ${ }^{2}$ Having unconditional worth further implies that those unable or potentially unable to make autonomous decisions, such as the very young, the mentally ill and others, should be protected. ${ }^{3}$

Mentally ill persons are regarded as potentially vulnerable to exploitation in research because their mental illness may inhibit their ability to give fully informed consent to participation. ${ }^{4}$ Many scholars have commented on whether mentally ill persons should be allowed to participate in research: in the past, some held that all research with mentally ill persons should be prohibited; others believed that research aimed at bettering the situation of the mentally ill had to be allowed under very circumscribed conditions; ${ }^{5}$ today, the quest is to ensure that mentally ill persons are protected against potential exploitation in research, and that appropriate research is undertaken to develop new knowledge in the service of this vulnerable group.

This contribution examines the statutory requirements relating to the informed consent of mentally ill persons to participation in clinical research in South Africa. Ethical research can only be undertaken if these requirements are met and the legal issues that frame the debate are considered.

The article is structured as follows: the juridical basis of informed consent in South African law is outlined before presenting the requirements for lawful consent developed in South African common law and case law. This is followed by a deliberation on the requirements for the participation of mentally ill persons in research as laid down by the Mental Health Care Act ${ }^{6}$ and its Regulations, ${ }^{7}$ the National Health $\mathrm{Act}^{8}$ and the Draft Regulations Relating to Research on Human Subjects, ${ }^{9}$ and the Constitution. ${ }^{10}$ As the article has a very specific focus - informed consent to participation in clinical research by mentally ill persons - the discussion on informed consent in South African common, case and statute law is limited to the law as it pertains to mentally ill adult ${ }^{11}$ persons; a discussion of the law on informed consent as it pertains to so-called pure 'therapeutic' research; and a discussion of the law as it pertains to controlled clinical trials and not to standard medical interventions or treatment.

\section{Juridical foundations of informed consent to research participation}

South African law regulates consent to participation in research as part of the wider concept of consent to medical intervention. Before the analysis of informed consent focuses on the Mental Health Care Act, the juridical foundation of informed consent in the South African common, case, statute and constitutional law is briefly established. Because common and case law do not deal with informed consent in a research setting, the general principles of informed consent to medical interventions need to be extrapolated to a research setting.

Under South African law, legal liability for wrongful (delictual) or unlawful (criminal) conduct during a medical intervention is based on one - or a combination of - the following: contractual liability, delictual liability, criminal liability, or professional censure for unprofessional or unethical conduct. ${ }^{12}$ Any medical intervention - whether therapeutic or experimental - is considered 
lawful only in the presence of certain grounds of justification. These are consent, necessity and negotiorum gestio ${ }^{13}$ |the list of justifications, however, is not closed). ${ }^{14}$ The general criterion determining lawfulness is the boni mores or legal convictions of society. ${ }^{15}$ The grounds of justification mentioned here are therefore merely crystallisations of the boni mores test for circumstances that frequently occur in practice.

Consent for lawful medical interventions is based on the principle or defence of volenti non fit iniuria, ${ }^{16}$ which in certain circumstances may exclude the wrongfulness or unlawfulness of a crime or delict: ${ }^{17}$ the literal meaning is 'no harm is done to someone who consents thereto'. ${ }^{18}$ Consent therefore excludes unlawfulness: 'where a person legally capable of expressing his will gives consent to injury or harm, the causing of such harm will be lawful'. ${ }^{19}$

Van Oosten outlines the requirements for legally valid informed consent: ${ }^{20}$

- Informed consent must be recognised by law: it must not be against the boni mores or public policy.

- The person who consents must have the legal capacity to consent, i.e. the consenting person must be legally and factually capable of understanding information and deciding on a course of action.

- The consent must be informed, i.e. information and comprehension should be present so that the consenting party knows what risks and benefits he or she is consenting to. ${ }^{21}$

- Consent should be free and voluntary, clear and unequivocal, and comprehensive. ${ }^{22}$

- It must be prior consent or consent given in advance; and it must be revocable. ${ }^{23}$

Certain requirements are particularly problematic in relation to research involving mentally ill individuals. Aspects of legal capacity to consent and the requirement that consent be free and informed are highlighted below.

\section{The person who consents must have the legal capacity to consent}

Consent is given by someone who is legally and factually capable of consenting; alternatively, proxy consent is allowed. ${ }^{24}$ Adults may lack legal capacity or competence to consent as a result of mental illness, or because they find themselves in a state of unconsciousness, or for other reasons. ${ }^{25}$ Not all mentally ill persons, even all institutionalised mentally ill persons, are legally incapable of consenting to participation in research. ${ }^{26}$ In the case of research on mentally ill persons, it must be assessed whether the mental disorder prevents the person from: (i) understanding to what he/she is consenting; (ii) choosing decisively for or against participation in research; (iii) communicating his/her choice; or (iv) accepting the need for an intervention. ${ }^{27}$ Werdie van Staden argues, congruent with current South African laws, that a functional approach ${ }^{28}$ to the question of whether a mentally ill and institutionalised person can give valid consent to participation in research requires that his/her capacity to give informed consent be assessed clinically rather than assumed by virtue of his/her belonging to a certain category of legal admission status. ${ }^{29}$

It is also possible that the nature of the research to be undertaken has an influence on whether mentally ill persons are considered suitable research participants. In this regard, a distinction is sometimes drawn between so-called 'therapeutic' and 'nontherapeutic' research. Therapeutic research investigates an intervention that is potentially of direct benefit to the participant (such as, for example, testing a new medication for obsessivecompulsive disorder in someone living with the disease); non-therapeutic research is aimed at acquiring generalised knowledge that may benefit persons other than the participant, and may be undertaken in healthy volunteers (such as, for example, testing a new medication for asthma in someone who is not living with the disease). ${ }^{30}$ Van Oosten argues that, although mentally ill persons may be capable of consenting to participation in medical research, their capacity to consent must 'be limited to therapeutic research on account of i) it's [sic] potential personal benefit; and ii) the undeniable potential of undue influence being exerted, wittingly or unwittingly, on such patients'. ${ }^{31}$ Generally, Van Oosten's view should be supported: non-therapeutic research may just as well be undertaken in a nonvulnerable population, avoiding exposing vulnerable research participants to unnecessary risks. So-called 'therapeutic research', aimed at alleviating the burden of disease of mentally ill persons, is acceptable if conducted in strict compliance with legal and constitutional imperatives.

\section{The consent must be informed and free ${ }^{32}$}

Consent cannot be judged informed unless the research participant knows what he or she is consenting to. Research participants are usually lay persons without scientific and medical knowledge. It is the responsibility of the researcher to provide the information that enables participants to make an informed decision.

In the case of a dispute, the court determines whether informed consent is present by examining the relevant circumstances and the facts of the case. ${ }^{33}$ The researcher or health care 
worker must not only show that she has provided the patient or research participant with information regarding the research or intervention, but that the information has been understood by the patient or research participant; ${ }^{34}$ that he or she 'appreciates and understands what the ... purpose ... is'. ${ }^{35}$ Of course, appreciation proposes more than mere knowledge, and the research participant must be able to meaningfully act on that information. C v Minister of Correctional Services is a case in point: ${ }^{36}$ the High Court found that, despite having twice been informed that a test was for HIV and other sexually transmitted diseases and that he had the right to refuse, C's (a prisoner's) consent had not been informed as he was not given the information in private, ${ }^{37}$ nor had he been given sufficient time to consider whether to refuse the test. ${ }^{38}$

Castell v De Greef places emphasis on what a reasonable patient would want to know about a procedure rather than the information considered essential by the doctor. The 'reasonable patient or person' standard requires that the information disclosed conforms to that which a (hypothetical) reasonable patient would want to know about the potential risks and benefits of the proposed procedure or treatment, as well as alternative treatment. ${ }^{39}$ The authority to determine what information to disclose to research participants has therefore shifted from doctors or researchers to patients or participants. ${ }^{40}$

Informed consent should be freely given and not be induced by fraud, fear or force. ${ }^{41}$ Only informed consent that is freely and voluntarily given can be considered as adhering to the patient's right of self-determination. Factors that influence the freedom and voluntariness of informed consent in a research setting, for example, are the fraudulent or negligent misrepresentation of the research (e.g. if a participant in research is under the impression that she is undergoing treatment instead of taking part in research, and if that misrepresentation can be ascribed to the researcher's intentional or negligent actions, the researcher may be held liable due to a lack of informed consent) ${ }^{42}$ and disproportionate financial incentives (if payment is given for participation in research in a setting in which participants are destitute and the payment is more than compensation for costs incurred and inconvenience suffered).

\section{The participation of mentally ill persons in clinical research in terms of the Constitution, 1996, and various statutes}

\section{The Constitution, 1996}

The Constitution of the Republic of South Africa, 1996, is the supreme law $w^{43}$ of the Republic. Any law or conduct in conflict with the Constitution is unconstitutional and void. ${ }^{44}$ Various rights guaranteed in the Constitution find application to the participation of mentally ill persons in research, namely the right to life, ${ }^{45}$ the right to human dignity, ${ }^{46}$ the right to equality, ${ }^{47}$ the right to privacy, $^{48}$ the right of access to health care, ${ }^{49}$ and, the focus of this discussion, the right to bodily and psychological integrity. ${ }^{50}$

The protection of informed consent in section 12(2)(c) of the Constitution reads as follows: '[e]veryone has the right to bodily and psychological integrity, which includes the right ... not to be subjected to medical or scientific experiments without their informed consent'. This subsection is part of the wider guarantee in section 12 to freedom and security of the person. Section 12 consists of two distinct parts: subsection 1, which deals with freedom and security of the person, and subsection 2, which deals with the right to bodily and psychological integrity, of which subsection 12(2)(c) is part. The right to autonomy underpins the right to make informed decisions about whether to participate in research. Research without informed consent would amount to a violation of one's bodily and psychological integrity.

Van Wyk is of the opinion that 'experimentation' as used in section 12(2)(c) probably means medical or scientific 'research'. . $^{1}$ The view is correct, given the fact that the two terms are used interchangeably in various international ethical documents and the National Health Act. ${ }^{52}$ The inclusion of the word 'or' indicates that 'scientific' is something different from 'medical'. 'Scientific' is certainly a term wider in meaning than medical; most medical experimentation may be termed 'scientific', but not all scientific experiments are 'medical'. Not only experimentation in the medical sciences but also other 'scientific' experiments conducted using human subjects fall under the ambit of section 12(2)(c). In this regard, is experimentation in, for example, the human sciences included in the term 'scientific', as human subjects are often used in such experiments? To my mind the answer to this question is positive: all experimentation on human subjects, whether in the human or natural sciences, requires the informed consent of research subjects. In addition, section 12(2)(c) makes no distinction between therapeutic and nontherapeutic experimentation, unlike the National Health Act. ${ }^{53}$ All experimentation without the participant's informed consent is prohibited, regardless of the category to which it belongs.

The use of the word 'their' in section 12(2)(c) has elicited scholarly argument. Van Oosten is of the opinion that the use of the word 'their' in the section prohibits surrogate consent. ${ }^{54}$ Of course, such a view has important consequences for research on mentally ill persons. However, I believe that this is an overly strict interpretation 
of the word 'their'. Van Wyk argues convincingly that Van Oosten's strict interpretation 'would preclude research in South Africa on legally incompetent people ... [and] would undeniably hinder medical progress ${ }^{15}$ for the very group of people in need of the research benefits. Van Wyk would therefore allow 'therapeutic' research on other than competent individuals, as long as the necessary surrogate consent has been obtained. ${ }^{56}$ It is submitted that non-therapeutic or 'scientific' research on incompetent people that carries more than minimal risk is not allowed under the South African Constitution. For example, efficacy trials for drugs treating other conditions than those specific to mentally ill persons - if they carry more than minimal risk - cannot be carried out on mentally ill persons.

\section{The Mental Health Care Act and its Regulations}

According to its Preamble, the Mental Health Care Act provides for the 'care, treatment and rehabilitation' of mentally ill persons. According to section 9, unless special circumstances prevail, such 'care, treatment and rehabilitation' may only be provided with the consent of the user. The Act sets out various procedures to be followed in the care, treatment and rehabilitation (including but not limited to institutional admission) of such mentally ill persons; it establishes Review Boards in respect of every health establishment; determines their powers and functions; provides for the care and administration of the property of mentally ill persons; and provides for matters connected therewith.

The Act defines a 'mental illness' in section 1 as 'a positive diagnosis of a mental health related illness in terms of accepted diagnostic criteria made by a mental health care practitioner authorised to make such diagnosis'. 'Mental health care' itself is not defined by the Mental Health Care Act; nor is it stated anywhere in the Act that 'mental health care' may include research. In fact, in light of the repeated emphasis in the Act on 'care, treatment and rehabilitation', it is very doubtful that 'mental heath care' should be understood to include mental health care research.

The Regulations made in terms of the Act provide for 'surgical procedures and medical or therapeutic treatment' in chapter 5. Once again the Regulations do not seem to make specific provision for mental health care research. In light of this, one has to turn to the National Health Act and its Draft Regulations.

\section{The National Health Act and its (Draft) Regulations}

With the enactment of the National Health Act, informed consent in research or experimentation became a statutory imperative.
Section 71(1) of the Act determines that: ${ }^{57}$

... research or experimentation on a living person may only be conducted in the prescribed manner; and with the written consent of the person after he or she has been informed of the object of the research or experimentation and any possible positive or negative consequences to his or her health.

The informational or knowledge aspect of informed consent is discussed in detail in sections $6(1)$ and $7(1)$ of the Act. According to section 6(1), informed consent encompasses knowledge about:

(a) the user's health status except in circumstances where there is substantial evidence that the disclosure of the user's health status would be contrary to her best interests;

(b) the range of diagnostic procedures and treatment options generally available;

(c) the benefits, risks, costs and consequences generally associated with each option; and

(d) the user's right to refuse health services and the implications, risks, obligations of such refusal.

Section 71(1) of the National Health Act requires that informed consent to participation in research be in writing. This departs from the previous common law position where no formalities were laid down for consent to participation in research. ${ }^{58}$

The National Health Act does not specifically provide for research in mentally ill persons - in fact, research in mentally ill persons is not mentioned expressly anywhere in the Act, despite the fact that another vulnerable group, children, is dealt with extensively with regard to their consent to participation in research. Instead, research in mentally ill persons is provided for in the Draft Regulations Relating to Research on Human Subjects. According to the Draft Regulations, research into mentally ill persons may be carried out on condition that:

(a) The research must strictly involve mental disability, so that it is necessary to involve persons who are mentally disabled;

(b) If the research is to be carried out on institutionalised persons, there must be sufficient justification for their involvement as the study population;

(c) Suitable evaluation procedures must be followed to confirm that the participant is capable of giving informed consent; 
(d) Consent by the person responsible for the participant must be free from coercion; and

(e) Research may only be carried out if no or minimal risk is involved. If the risk is minimal, it should be outweighed by the anticipated benefits to the participants.

It is concluded that mentally ill persons, if competent to do so, must give informed consent to participation in research themselves. Next, only research relating to their mental illness (so-called 'therapeutic' research) is permitted. If 'institutionalised' mentally ill persons are to be participants, there must be sufficient reason for their inclusion: 'there must be sufficient justification for their involvement as the study population'; and the ability of the participant to give informed consent must be clinically assessed and judged on a case-by-case-basis (in support of Van Staden's argument for a 'functional' approach to consent). Further, according to subsection (e), only where there is no more than 'minimal risk' may the research be carried out in mentally ill persons. 'Minimal risk' is defined by the Draft Regulations as a probability and magnitude of harm or discomfort no greater than that ordinarily encountered in daily life. 'Minimal risk' is justified only if it is outweighed by the anticipated benefits to the participants.

\section{Conclusion}

South African common law and case law on informed consent do not deal specifically with informed consent in a research setting, and common law and case law do not deal with the informed consent of mentally ill persons to participation in research. In consequence it is necessary to extrapolate general principles to the research setting involving mentally ill persons. With the exception of the Draft Regulations Relating to Research on Human Subjects published for comment in terms of the National Health Act, no statute provides specifically and comprehensively for the informed consent of mentally ill persons to research participation. The achievement of this is a goal that needs to be worked towards. At present chapter 8 of the National Health Act is being extensively redrafted, an outcome of which it is hoped will deal judiciously with the consent of mentally ill persons to participation in research.

\section{References}

1. Katz J. Experimentation with Human Beings: The Authority of the Investigator, Subject, Professions and State in the Human Experimentation Process. New York: Russel Sage, 1972: 532.

2. Beauchamp TL, Childress JF. Principles of Biomedical Ethics. 5th ed. Oxford: Oxford University Press, 2001: 63. (See also Gillon R. Philosophical Medical Ethics.
Chichester: John Wiley \& Sons, 1994: 63-64, where he presents Kant's argument in favour of respecting autonomy.)

3. Smith T. Ethics in Medical Research: A Handbook of Good Practice. Cambridge: Cambridge University Press, 1999: 6.

4. I use 'perceived' because research seems to indicate that this perception may be misplaced - see e.g. Appelbaum PS. Rethinking the conduct of psychiatric research. Arch Gen Psychiatry 1997;54:1 17-120. Robert Michaels writes: 'The greater problem is that too little research is conducted on their [mentally ill persons'] behalf. Psychiatric research is burdened by a long history of public fear of mental illness, prejudice against the mentally ill, and distrust of those who treat or study them' (Michaels R. Are research ethics bad for our mental health? N Engl J Med 1999;340: 1427-1430).

5. See Schüklenk U. Protecting the vulnerable: Testing times for research ethics. Soc Sci Med 2000:51:969-977. Prohibiting mentally ill persons from participation in research is no longer a serious contention, however

6. Republic of South Africa. Mental Health Care Act No. 17 of 2002.

7. Republic of South Africa. Mental Health Care Act No. 17 of 2002. General Regulations. Government Gazette 2004, vol. 474, No. 27117.

8. Republic of South Africa. National Health Act No. 61 of 2003.

9. Republic of South Africa. GN R 1467. Government Gazette 27117 of 15 December 2004

10. Republic of South Africa. Constitution, 1996.

11. A discussion of the participation of mentally ill children in research falls outside the scope of this contribution.

12. Carstens P, Pearmain D. Principles of South African Medical Law. Durban: LexisNexis Butterworths, 2007: 872

13. Strauss S. Doctor, Patient and the Law: A Selection of Practical Issues. Pretoria: J L van Schaik, 1991: 31. Other commentators mention additional grounds, such as therapeutic privilege, unauthorised administration or agency, and relative impossibility (see Carstens and Pearmain 2007: 873).

14. Snyman CR. Strafreg. Durban: LexisNexis Butterworths, 2006: 95

15. See e.g. Clarke v Hurst 1992 (4) SA 630 (D) 653B, also Neethling J, et al. The Law of Delict. Durban: Butterworths, 2006: 70.

16. The ground of justification of consent is based on the rule that when a legally competent person consents to an action which would otherwise be unlawful, that infringement of her rights is regarded as lawful (Van Oosten FW. The doctrine of informed consent in medical law. Unpublished LLD thesis, University of South Africa, 1989: 23). Similar grounds of justification exist in other countries; however, they are not always based on the doctrine of volenti non fit iniuria, but on the doctor's duty of care towards his/her patient (see Rodgers $\vee$ Whitaker (1993) 67 ALIR 47).

17. As above; Stoffberg v Elliott 1923 CPD 148.

18. McKerron, cited in Lampert v Hefer 19552 SA 507 (AD) 512

19. Neethling 2006: 89

20. Van Oosten 1989: 17-25

21. Carstens and Pearmain 2007: 878

22. Also see Christian Lawyers Association v Minister of Health 1998 (4) SA 1102 (W), where the Court stated that the woman has to 'subjectively' consent and that her consent must be comprehensive in that it must cover the entire transaction and its consequences

23. Because consent is a unilateral act, it may be unilaterally revoked by the consenting party at any stage before the defendant's conduct (Neethling et al. 2006: 91).

24. Van Oosten FW. The law and ethics of information and consent in medical research Journal of Contemporary Roman Dutch Law 2000;63:5-10. See also the extensive discussion by Carstens and Pearmain 2007: 897-905.

25. On the capacity of mentally ill persons to consent to medical interventions, see Carstens and Pearmain 2007: 899-902

26. Van Oosten 1989: 5-18.

27. Van Staden CW, Kruger C. Incapacity to give informed consent owing to mental disorder. J Med Ethics 2003;29:41 - 3; Van Staden CW. Can involuntary admitted patients give informed consent to participation in research? South African Journal of Psychiatry 2007;1 3:10-12.

28. Rather than a categorical approach which predicates that people should be considered incapable by virtue of their belonging to a certain category, for example, being involuntarily admitted to a psychiatric hospital (Van Staden 2007: 10).

29. As above.

30. The distinction between therapeutic and non-therapeutic research is regarded as too narrow: non-therapeutic research has many therapeutic elements; therapeutic research often has non-therapeutic elements; MRC. Ethics Book 1:9.12.

31. Van Oosten 1989: 16

32. Castell $\vee$ De Greef 1994 (4) SA 408 (C). This case may be regarded as the locus classicus on informed consent in South African law.

33. Neethling et al. 2006: 92. The onus of establishing liability for an intervention without informed consent lies with the plaintiff (in a civil case) and the state (in a criminal case). Once a prima facie case of non-disclosure has been established, the doctor will have to refute the allegation of non-disclosure by providing evidence that the patient had indeed given informed consent (Carstens and Pearmain 2007: 891) 


\section{Philosophy \& Ethics}

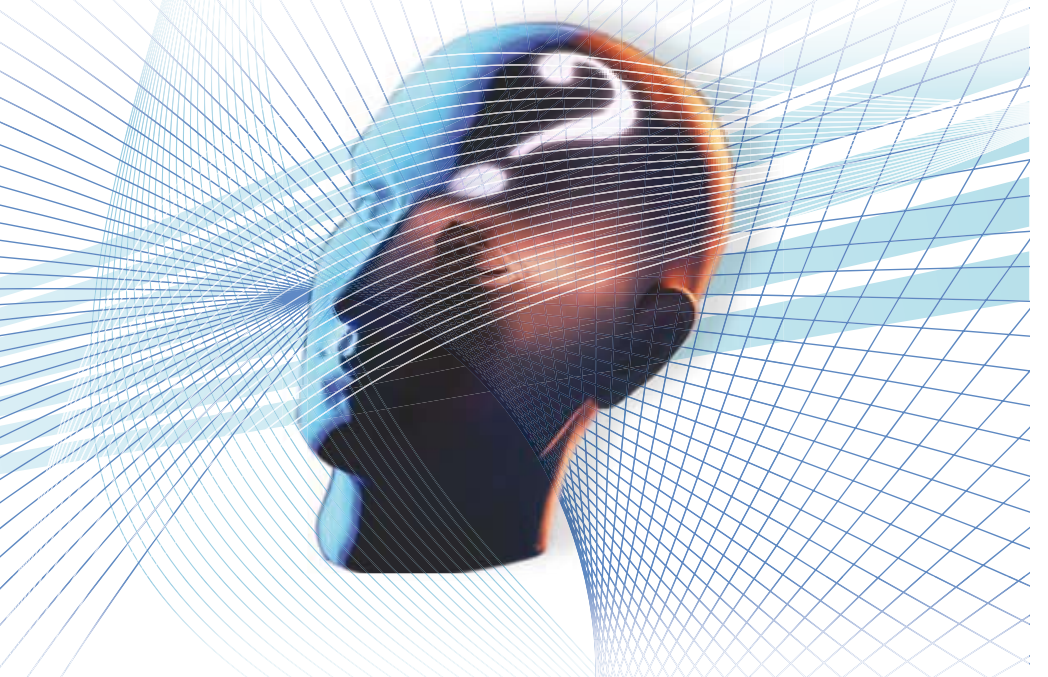

The University of Pretoria, one of South Africa's foremost research institutions, now offers a Master's course (MPhil) in Philosophy \& Ethics of Mental Health in the Department of Psychiatry, Faculty of Health Sciences.

The course offers seminars, e-learning, case studies and guided writing of a dissertation. Candidates are offered a wide choice of content, as well as publication and $\mathrm{PhD}$ opportunities.

The course offers philosophical skills and insight into mental health to:

- Mental health practitioners

- Philosophers

For more information, visit www.up.ac.za/pemh or email the course director, Prof. Werdie van Staden at werdie.vanstaden@up.ac.za

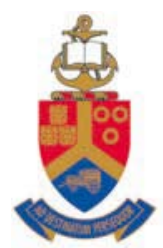

UNIVERSITEIT VAN PRETORIA UNIVERSITY OF PRETORIA YUNIBESITHI YA PRETORIA Faculty of Health Sciences
34. See C v Minister of Correctional Services 1996 (4) SA 292 (T). My emphasis. Ngwena remarks: 'Pre and post [test] counselling are integral to informed consent requirements in view of the serious implications of an HIV positive result' (Ngwena C. Constitutional values and HIV/AIDS in the workplace: Reflections on Hoffmann v South African Airways. Developing World Bioethics 2001; 1:42-55).

35. Van Oosten 1989: 24. Of course, appreciation implies more than mere knowledge.

36. C v Minister of Correctional Services 301D.

37. 304C-E.

38. As above. In Christian Lawyers Association v Minister of Health 1998 (4) SA 1102 (W), where the Court had to interpret the meaning of 'informed consent' as it is used in the Choice on Termination of Pregnancy Act No. 92 of 1996, Mojapelo J observed that in South African law informed consent rests on three legs: knowledge, appreciation and consent. He supports the definition given in Waring and Gillow v Sherbourne 1904 TS 340, where the Court remarked that 'It must be clearly shown that the risk was known, that it was realised, that it was voluntarily undertaken. Knowledge, appreciation, consent - these are the essential elements; but knowledge does not invariably imply appreciation; and both together are not necessarily equivalent to consent' (344). According to Mojapelo, a woman who consents to the termination of her pregnancy must also 'comprehend and understand the nature and extent of the harm or risk'.

39. $426 \mathrm{~F}-\mathrm{G}$

40. The approach in Castell $\vee$ De Greef contrasts with that previously held in Richter v Estate Hammann 1976 (3) SA 226 (C), in which the court adopted a 'reasonable doctor' standard: 'in principle his conduct should be tested by the standard of the reasonable doctor faced with the particular problem. In reaching a conclusion a court should be guided by medical opinion as to what a reasonable doctor, having regard to all the circumstances of a particular case, should or should not do' $(2323 \mathrm{H})$.

41. Van Oosten 2000: 29

42. See Neethling et al. 2006: 302-306

43. Constitution: section 2.

44. Constitution: section 2; Executive Council of the Western Cape Legislature v President of the Republic of South Africa 1995 (4) SA 877 (CC) para 62; Fose v Minister of Safety and Security 1997 (3) SA 786 para 87.

45. Constitution: section 1].

46. Constitution: section 10

47. Constitution: section 9 .

48. Constitution: section 14

49. Constitution: section $27(1)(a)$

50. Constitution: section 12(2).

51. Van Wyk C. HIV preventative vaccine research on children: Is this possible in terms of South African law and research guidelines? Journal for Contemporary Roman Dutch Law 2005:68:35-38.

52. The Nuremberg Code refers to 'experimentation'; the CIOMS Guidelines refer to 'research'; the Declaration of Helsinki refers to 'experimentation' and 'research'. The National Health Act refers to 'experimentation' and 'research' as alternatives for the same concept.

53. See Nienaber A. The statutory regulation of children's participation in HIV-related clinical research: More questions than answers. Journal for Contemporary Roman Dutch Law 2008;71:671-677

54. Van Oosten 1989: 9

55. Van Wyk 2005: 38

56. See Van Wyk C. Clinical trials, medical research and cloning in South Africa. Journal for Contemporary Roman Dutch Law 2004;67: 1-8

57. My emphasis. The National Health Act entered into force in 2006, but ch. 9, which deals with issues related to health research, had not yet come into effect as of 1 September 2010.

58. See Nienaber A. The researcher's liability for HIV-related clinical research without the participant's informed consent: South Africa's common law, case law and legislation. Journal for Contemporary Roman Dutch Law 2008;71:364-386.
Universiteit van Pretoria • University of Pretoria

- Yunibesithi ya Pretoria

Pretoria 0002 Suid-Afrika • South Africa • Africa Borwa

Tel: +27 (0) 124203111 • Faks / Fax: +27 (0) 124204555

info@up.ac.za・www.up.ac.za 